No. 11(18)

\title{
ANALYSIS OF CONSUMER INNOVATIVENESS IN AN AXIOMATIC APPROACH ${ }^{1}$
}

\section{Beata Ciałowicz}

\begin{abstract}
In the Schumpeterian vision of economic development economic evolution is based on the innovative activities of producers and evolutionary changes in the production sphere realized through credits created by banks from savings. The possibility of innovative changes in the demand sphere and the active role of consumers in innovative processes are neglected. Hence the main aim of this paper is an extension of the previous results obtain in the formal modelling of Schumpeter's theory through the axiomatical analysis of innovative changes in the consumer in the formal apparatus of the modern Arrow-Debreu theory of general equilibrium.
\end{abstract}

Keywords: innovation, Arrow-Debreu model, Schumpeter's theory.

JEL Classification: O31, O10, C6.

DOI: $10.15611 /$ me.2015.10.02.

\section{Introduction}

One of the main topics of evolutionary economics, in particular based on Schumpeter's theory of economic development [Schumpeter 1961], is the analysis of the innovative activities of producers and evolutionary changes in the production sphere. According to this theory, the main causes of economic development are innovations implemented by producersinnovators and realized through credits created by banks from savings. Consumers play a passive role in this process and they can be characterized by their routine behaviour, so changes in their activities are secondary to the respective changes in the production system. The innovative changes in the demand sphere and the active role of consumers in the innovative processes are neglected. This idea was reflected in a large part of the mainstream formalizations of the Schumpeterian theory of economic development (cf. [Nelson, Winter 1982; 2002]).

\footnotetext{
Beata Cialowicz

Department of Mathematics, Cracow University of Economics

beata.cialowicz@uek.krakow.pl

${ }^{1}$ This work was supported by Polish National Science Centre Grant no. UMO2014/13/B/HS4/00552.
} 
In the formal modeling of the Shumpeterian vision of innovative development in the Arrow-Debreu theory of general equilibrium, initiated in the 1990s and still continued (cf. [Malawski 1999, 2005, 2013; Ciałowicz, Malawski 2011; 2012; 2013]) the active role of the demand side in the process of economic development and innovative changes in this sphere are also omitted. However, in spite of the originality and theoretical significance of Schumpeter's approach, the idea that economic evolution is an immensely complex process and demand-side aspects play an important role in this process, has received increased attention in recent years, especially in the neo-Schumpeterian modern setting [Saam 2005; NESTA 2010; Andersen 2007; Green et al. 2002].

Hence the main aim of this paper is to develop and deepen the previous results obtained in the formal modelling of Schumpeter's theory of economic development through the axiomatical analysis of the phenomenon of consumer's innovativeness and the innovative changes in the consumer sphere, taking into account a specific structure of a set of consumers and a specific structure of space of commodities, in the formal apparatus of the modern Arrow-Debreu theory of general equilibrium.

This setting is coherent with a currently active - in spite of Schumpeter's theory - research path which emphasizes the active role of consumers in the innovation processes. Moreover, given the axiomatical analysis of innovative changes in the demand sphere includes the basic elements of the mathematical formalism, which constitute the starting point for further research on the impact of the demand sphere on the process of innovative development of the whole economic system.

\section{Model of the Debreu private ownership economy}

The formal modeling of Schumpeter's theory of economic development in the mathematical framework of the Arrow-Debreu general equilibrium theory [Malawski 1999; 2005; Ciałowicz, Malawski 2011] enables us to study the standard model of the Debreu economy with private ownership [Debreu 1959] in the form of a multi-range relational system as a specific combination of the production and consumption systems.

The production system is represented by a two-range relational system in the form:

$$
P=\left(B, \mathbb{R}^{\ell}, C h_{P}\right) \text {, where } C h_{P}=(y, p, \eta, \pi)
$$

is a characteristic of system $P$. In this system, each producer $b$ from the set 
$B=\left\{b_{1}, \ldots, b_{n}\right\}$ operates on $\ell$-dimensional commodity space $\mathbb{R}^{\ell}$ and his/her activities are limited to the nonempty set of feasible production plans $Y_{b}$, according to a correspondence of production sets

$$
y \subset B \times P\left(\mathbb{R}^{\ell}\right) \text {, where } y(b):=Y_{b} \subset \mathbb{R}^{\ell} .
$$

The role of each producer is to choose and perform the production plans maximizing his/her profit in a given price system $p$ and technologies. This fact is described by a correspondence of supply $\eta \subset B \times P\left(\mathbb{R}^{\ell}\right)$ such that for each

$$
b=1, \ldots, n, \eta(b):=\eta_{b}(p):=\left\{y_{b}^{\prime} \in Y_{b}: p y_{b}^{\prime}=\max _{y_{b} \in Y_{b}} p y_{b}\right\} \neq \varnothing,
$$

and measured by the maximum profit function $\pi \subset B \times \mathbb{R}$, i.e. for each

$$
b=1, \ldots, n \pi(b):=\pi_{b}(p):=\max _{y_{b} \in Y_{b}} p y_{b} .
$$

Similarly, the formal model of the consumption system is represented by a three-range relational system:

$$
C=\left(A, \mathbb{R}^{\ell}, \text { Pref }, C h_{C}\right), \quad \text { where } \quad C h_{C}=(x, e, \varepsilon, p, \beta, \varphi)
$$

is a characteristic of system $C$. In this system each consumer from the set $A=\left\{a_{1}, \ldots, a_{m}\right\}$ chooses and performs the consumption plans maximizing his/her preference relation in a given price system $p$ on his/her budget set.

Consumer $a \in A$ operates on $\ell$-dimensional commodity space $\mathbb{R}^{\ell}$ and is characterized by his/her nonempty consumption set $X_{a} \subset \mathbb{R}^{\ell}$, an initial endowment $e_{a} \in \mathbb{R}^{\ell}$ and preference relation $\preceq_{a} \in$ Pref . The consumption possibilities are assigned to him/her according to the correspondence of consumption sets $x \subset A \times P\left(\mathbb{R}^{\ell}\right)$ such that $x(a):=X_{a} \subset \mathbb{R}^{\ell}$. Initial endowment is assigned by the mapping $e \subset A \times \mathbb{R}^{\ell}$ such that $e(a):=e_{a} \in X_{a}$. A preference relation is determined by the correspondence $\varepsilon \subset A \times P\left(\mathbb{R}^{2 \ell}\right)$, which to every consumer assigns a preference relation $\preceq_{a} \in$ Pref (restricted to the consumption set $X_{a}$ ), where Pref is the family of all preference relations $\preceq_{a} \subset \mathbb{R}^{2 \ell}$ defined on the commodity space. Each consumer is also characterized by his/her budget set $\beta_{a}$, described by the correspondence $\beta \subset A \times P\left(\mathbb{R}^{\ell}\right)$ such that $\beta_{a}=\beta(a):=\beta_{\left(p, e_{a}\right)}(a):=\left\{x_{a} \in X_{a}: p x_{a} \leq p e_{a}\right\}$ is nonempty. The role of the consumer is to choose and perform the consump- 
tion plans maximizing its preference relation in budget set $\beta_{a}$. This fact is described by a correspondence of demand $\varphi \subset A \times P\left(\mathbb{R}^{\ell}\right)$ such that

$$
\varphi(a):=\varphi_{\left(\varepsilon(a), p, e_{a}\right)}(a):=\left\{x \in \beta_{a}: \forall x^{\prime} \in \beta_{a} \quad x^{\prime} \preceq_{a} x\right\} \neq \varnothing .
$$

The Debreu private ownership economy $E_{p}$ is a combination of production system $P$ and consumption system $C$, such that the consumers share in the producers' profits. The shares are measured by a mapping $\theta \subset(A \times B) \times \mathbb{R}_{+}$, i.e. for every $(a, b) \in A \times B$ the number $\theta_{a b}:=\theta(a, b) \in[0,1]$ describes the consumer $a$ 's share in the producer $b$ 's profit, and there is, for every $b \in B, \sum_{a \in A} \theta_{a b}=1$. Moreover, some fixed (initial) total resource $\varpi \in \mathbb{R}^{\ell}$ of the economy $E_{p}$ is the consumers' property, i.e. $\varpi:=\sum_{a \in A} e_{a}$. This means that the budget set correspondence $\beta$ is modified for the economy $E_{p}$, so that the expenditure of consumer $a$ does not exceed the value $w_{a}=p e_{a}+\sum_{b \in B} \theta_{a b} \pi_{b}(p)$. Then

$$
\beta_{a}:=\beta_{\left(p, e_{a}\right)}(a):=\left\{x_{a} \in X_{a}: p x_{a} \leq w_{a}\right\} .
$$

Thus the private ownership economy $E_{p}$ can be concisely described in the form of multi-range relational system: $E_{p}=\left(\mathbb{R}^{\ell}, P, C, \theta, \varpi\right)$.

\section{Innovative commodities}

An axiomatic analysis of Schumpeter's theory of economic development in the Arrow-Debreu set-up is based on specific extensions of the formal model of an economy with private ownership (cf. [Malawski 1999, 2013; Ciałowicz, Malawski 2011, 2012]) such as cumulative and innovative extensions, which modeled two basic forms of economic life analyzed by Schumpeter: circular flow and economic development. Thus, a formal definition of an innovative commodity, meaning a commodity which can be called innovative with respect to its character or new technologies used in its production, is based on a definition of an innovative extension of the Debreu economy. According to the assumption that producers play a leading role in Schumpeterian innovative evolution, we first recall the definition of innovative extension of a production system. 
Definition 1 [Ciałowicz, Malawski 2011; Malawski 2013]. A production system $\bar{P}=\left(\bar{B}, \mathbb{R}^{\bar{l}} ; \bar{y}, \bar{p}, \bar{\eta}, \bar{\pi}\right)$ is called an innovative extension of a system $P=\left(B, \mathbb{R}^{\ell} ; y, p, \eta, \pi\right)$, shortly $P \subset_{i} \bar{P}$, if:

$1 \ell \leq \bar{\ell}$

$2 p=\operatorname{proj}_{\mathbb{R}^{\ell}}(\bar{p})$

$3 \exists \bar{b} \in \bar{B} \quad \forall b \in B$

$3.1 \operatorname{proj}_{\mathbb{R}^{e}}\left(\bar{Y}_{\bar{b}}\right) \not \subset Y_{b}$

$3.2 \operatorname{proj}_{\mathbb{R}^{\ell}}\left(\bar{\eta}_{\bar{b}}(\bar{p})\right) \not \subset \eta_{b}(p)$

$3.3 \pi_{b}(p)<\bar{\pi}_{\bar{b}}(\bar{p})$.

The above definition says that $\bar{P}$ is an innovative extension of system $P$, if there appears at least one specific producer $\bar{b} \in \bar{B}$, such that for each $b \in B$ there exists a production plan $\bar{y}_{\bar{b}} \in \bar{Y}_{\bar{b}}$ and $\operatorname{proj}_{\mathbb{R}^{\ell}}\left(\bar{y}_{\bar{b}}\right) \notin Y_{b}$. Producer $\bar{b}$ is called an innovator and designated production plans $\bar{y}_{\bar{b}}$ for which $\operatorname{proj}_{\mathbb{R}^{\ell}}\left(\bar{y}_{\bar{b}}\right) \notin \eta_{b}(p)$ and $\bar{\pi}_{\bar{b}}(\bar{y})=\bar{y} \cdot \bar{y}_{\bar{b}}>\pi_{b}(p)$ are called innovative (Conditions 3.2 and 3.3). This means that innovative production plans are optimal for the producer-innovator and cannot be reduced to the analogous plans being realized by the producers in the previous production system $P$. Moreover, we assume that the number of possible commodities on the market does not decrease (Condition 1), and the prices of "old" products do not change (Condition 2) in the set of all innovative production plans $y_{b^{\prime}}^{\prime}$.

Notice that the strict version of Condition $1, \ell<\bar{\ell}$ means that radical innovations occur in the form of at least one completely new good or service, whereas $\ell=\bar{\ell}$ corresponds to incremental innovations in technologies.

According to Schumpeter's theory, innovative changes in the production sphere determine changes in the private ownership economy. This leads us to the definition of an innovative extension of the whole economic system $E_{p}$ :

Definition 2 [Ciałowicz, Malawski 2011; Malawski 2013]. An economic system $\bar{E}_{p}=\left(\mathbb{R}^{\bar{\ell}}, \bar{P}, \bar{C}, \bar{\theta}, \overline{\bar{\omega}}\right)$, is called innovative extension of a system $E_{p}=\left(\mathbb{R}^{\ell}, P, C, \theta, \varpi\right)$, shortly $E_{p} \subset_{i} \bar{E}_{p}$, if:

$$
P \subset_{i} \bar{P} \text {, where } P=\left(B, \mathbb{R}^{\ell}, C h_{P}\right), \bar{P}=\left(\bar{B}, \mathbb{R}^{\bar{\ell}}, C h_{\bar{P}}\right) .
$$


The above definitions enable us to define innovative products in the space of commodities.

Definition 3. Let two production systems $\bar{P}, P$ are given and $P \subset_{i} \bar{P}$ (Definition 1). Commodity $k \in\{1,2, \ldots, \bar{\ell}\}$ is called innovative if $\ell<k \leq \bar{\ell}$ or $k \leq \ell$ and there exist producer-innovator $\bar{b} \in \bar{B}$ and its innovative production plan $\bar{y}_{\bar{b}}=\left(\bar{y}_{1}, \bar{y}_{2}, \ldots, \bar{y}_{\bar{\ell}}\right) \in \bar{Y}_{\bar{b}}$ such that for any producer $b \in B$ and production plan $y_{b}=\left(y_{1}, y_{2}, \ldots, y_{\ell}\right) \in Y_{b} \quad \bar{y}_{k} \neq y_{k}$.

The above definition says that an innovative commodity is a new product introduced in the economy $(\ell<k \leq \bar{\ell})$ or a commodity for which new methods of production are introduced. This means that in the innovative extension of a production system a new product or commodity may appear or innovative changes are observed in the production process of a distinguished commodity $k$. Moreover, for non-innovative products there is no change in the level of production, which means if $k^{\prime} \neq k$ then $\bar{y}_{k^{\prime}}=y_{k^{\prime}}$.

According to the definition in the space of commodity $\mathbb{R}^{\bar{\ell}}$ we may distinguish the subspace of innovative products. Thus, let the space of commodities have the form: $\mathbb{R}^{\bar{\ell}}=\mathbb{R}^{\ell_{n}+\ell_{I}}$, where:

- $\mathbb{R}^{\ell_{I}}$ is the space of innovative commodities,

- $\mathbb{R}^{\ell_{n}}$ is the space of non-innovative commodities.

This means that if $\ell=\bar{\ell}$ then for each innovative production plan $\bar{y}_{\bar{b}} \in \bar{Y}_{\bar{b}}$ and each production plan $y_{b} \in Y_{b}$ for $k=1,2, \ldots, \bar{\ell}$ such that $\bar{y}_{k} \neq y_{k}$ we have $k \in\left\{1,2, \ldots, \ell_{I}\right\}$ and for $k^{\prime} \neq k$ such that $\bar{y}_{k^{\prime}}=y_{k^{\prime}}$ we have $k^{\prime} \in\left\{1,2, \ldots, \ell_{n}\right\}$.

Similarly we may introduce the subspace of innovative commodities in the whole Debreu economy according to the definition of its innovative extension.

\section{Consumer innovativeness and innovative changes in the consumers' sphere}

Many empirical researchers consider consumer innovativeness as a personality trait relating to an individual willingness to accept change [Clark, Goldsmith 2006; Hurt, Joseph, Cook 1977]. Rogers and Shoemaker [1971], define innovativeness as the degree to which an individual is relatively 
earlier in adopting an innovation than other members of his social system. In this study, consumer innovativeness is defined as an innovative predisposition which is the degree to which the individual is willing to adoption innovations such as goods and services or new ideas. Moreover, consumer innovativeness can be seen from two different perspectives. First, the consumer as a company owner plays an active role in choosing the optimal innovative production plans. Second, consumer innovativeness is visible in its attitude toward innovative commodities. This means that we can distinguish two kinds of consumer innovativeness:

1. The innovativeness of consumers as shareholders in producers' profits based on the specific production-preference relation. It may affect the choice of the innovative production plans because it will be the role of consumers to choose optimal production plans with respect to their specific production-preferences they are endowed with, but on the other hand producers carry them out being equipped with suitable technologies. However, it turns out that these two mechanisms are not equivalent, leading to different results, which have been studied before (cf. [Ciałowicz, Malawski 2010; 2011; Malawski 2013]). It was proved that innovative changes in the production sphere and the whole Debreu economy are stimulated by consumers endowed with pro-innovative production-preference relations.

2. The innovativeness of consumers as the predisposition of a consumer to adopt an innovative product revealed in their individual preference relation and connected with preferences for innovative commodities in consumption plans. In this case, innovativeness refers to the "successful" exploitation of new ideas. Demand in this context refers to the desire or preference to purchase an innovative good or service.

The modification of the Debreu economy introduced in the previous chapters gives the possibility to analyze the second kind of consumer innovativeness and to define the pro-innovative preference relation of a consumer with respect to innovative commodities, introduce innovative consumption plans and finally give a definition of an innovative extension of the consumption system.

Let the Debreu economy $E_{p}=\left(\mathbb{R}^{\ell}, P, C, \theta, \omega\right)$ and its innovative extension $\bar{E}_{p}=\left(\mathbb{R}^{\bar{\ell}}, \bar{P}, \bar{C}, \bar{\theta}, \overline{\bar{\omega}}\right)$ are given.

For the purpose of this research, let us focus on consumption system $\bar{C}$ as a subsystem of economy $\bar{E}_{p}$ with innovative commodities and $\mathbb{R}^{\bar{\ell}}=\mathbb{R}^{\bar{\ell}_{n}+\ell_{I}}$. 
Notice that according to consumers' convention, an innovative commodity can be an input in a consumption plan represented by non-positive coordinates (what he/she consumes; what is made available to him/her) or the output represented by non-negative coordinates (what he/she produces; what is made available by him/her; typically human labour). In accordance with the aim of this work, we will focus on consumer innovativeness (of the second kind) connected only with innovative commodities as inputs in consumption plans.

In the next definition the standard inequalities in $\ell$-dimensional space $\mathbb{R}^{\ell}$ are used:

a) $x \leq y \Leftrightarrow x_{k} \leq y_{k}$ for each $k=1,2, \ldots, \ell$,

b) $x<y \Leftrightarrow x \leq y$ i $x \neq y$,

c) $x \ll y \Leftrightarrow x_{k}<y_{k}$ for each $k=1,2, \ldots, \ell$,

for $x, y \in \mathbb{R}^{\ell}$, where $x=\left(x_{1}, x_{2}, \ldots, x_{\ell}\right), y=\left(y_{1}, y_{2}, \ldots, y_{\ell}\right)$ :

Let $\operatorname{proj}_{\mathbb{R}^{\bar{t}_{I}}}(\bar{x})$ stands for orthogonal projection of a vector $\bar{x}$ onto the subspace of innovative commodities $\mathbb{R}^{\bar{\ell}_{I}}$ (in the standard basis).

Definition 4. A consumption plan $\bar{x} \in \mathbb{R}^{\bar{\ell}}$ is called innovative if $\operatorname{proj}_{\mathbb{R}^{\bar{T}_{I}}}(\bar{x})>0$, where $0=(0,0, \ldots, 0)$.

According to the definition, a consumption plan is called innovative if among all the inputs (non-negative coordinates) there is at least one innovative commodity.

The innovative consumption plans can serve the tools for introducing a kind of partition in the set of the possible consumptions of the consumer with respect to the psycho-physical constraint of this individual and in his/her budget set. Thus, for each consumer $\bar{a} \in \bar{A}$ let us divide set $\bar{X}(\bar{a})=\bar{X}_{\bar{a}}$ into two disjoint subsets $\bar{X}_{\bar{a}}^{n}$ and $\bar{X}_{\bar{a}}^{I}$ such that $\bar{X}_{\bar{a}}=\bar{X}_{\bar{a}}^{n} \cup \bar{X}_{\bar{a}}^{I}$ and $\bar{X}_{\bar{a}}^{n} \cap \bar{X}_{\bar{a}}^{I}=\varnothing$ where $\bar{X}_{\bar{a}}^{I}$ is a set of innovative consumption plans, $\bar{X}_{\bar{a}}^{n}$ is a set of non-innovative consumption plans. Similarly we can divide budget set $\bar{\beta}_{\bar{a}}$ into two disjoint subsets $\bar{\beta}_{\bar{a}}^{n}$ and $\bar{\beta}_{\bar{a}}^{I}$.

Definition 5. A consumption plan $\bar{x}^{\prime} \in \mathbb{R}^{\bar{\ell}}$ is called:

a) at least as innovative as plan $\bar{x} \in \mathbb{R}^{\bar{\ell}}$ (in short: $\bar{x} \leq_{I} \bar{x}^{\prime}$ ) if:

$$
\operatorname{proj}_{\mathbb{R}^{\bar{T}_{I}}}(\bar{x}) \leq \operatorname{proj}_{\mathbb{R}^{\bar{T}_{I}}}\left(\bar{x}^{\prime}\right),
$$


b) more innovative than plan $\bar{x} \in \mathbb{R}^{\bar{\ell}}$ (in short: $\bar{x}<_{I} \bar{x}^{\prime}$ ) if:

$$
\operatorname{proj}_{\mathbb{R}^{\bar{I}_{I}}}(\bar{x})<\operatorname{proj}_{\mathbb{R}^{\bar{I}_{I}}}\left(\bar{x}^{\prime}\right) \text {. }
$$

According to the above definition, a consumption plan is more innovative than other plans if all its coordinates representing innovative commodities are not less than the corresponding coordinates, and at least one of them is greater. Notice that this relation occurs in cases when plan $\bar{X}$ is noninnovative and $\operatorname{proj}_{\mathbb{R}^{\bar{I}_{I}}}(\bar{x})=0$ as well.

Remark. A relation $\bar{x} \leq_{I} \bar{x}^{\prime} \Leftrightarrow \operatorname{proj}_{\mathbb{R}^{\bar{T}_{I}}}(\bar{x}) \leq \operatorname{proj}_{\mathbb{R}^{\bar{T}_{I}}}\left(\bar{x}^{\prime}\right)$ is pre-order (quasi-order) in space $\mathbb{R}^{\bar{\ell}}$, because this relation is:

a) reflexive $\Leftrightarrow \forall \bar{x} \in \mathbb{R}^{\bar{\ell}}\left[\bar{x} \leq_{I} \bar{x} \Leftrightarrow \operatorname{proj}_{\mathbb{R}^{\bar{t}_{I}}}(\bar{x}) \leq \operatorname{proj}_{\mathbb{R}^{\bar{\ell}_{I}}}(\bar{x})\right]$,

b) transitive $\Leftrightarrow \forall \bar{x}, \bar{x}^{\prime}, \bar{x}^{\prime \prime} \in \mathbb{R}^{\bar{\ell}}\left[\left(\bar{x} \leq_{I} \bar{x}^{\prime} \wedge \bar{x}^{\prime} \leq_{I} \bar{x}^{\prime \prime}\right) \Rightarrow \bar{x}^{\prime} \leq_{I} \bar{x}^{\prime \prime}\right]$.

Definition 6. Preference relation $\preceq_{\bar{a}} \subset \mathbb{R}^{\bar{\ell}} \times \mathbb{R}^{\bar{\ell}}$ of consumer $\bar{a} \in \bar{A}$ is called pro-innovative if for any consumption plans $\bar{x}_{\bar{a}}, \bar{x}_{\bar{a}} \in X_{\bar{a}}$ we have $\bar{x}_{\bar{a}} \prec_{\bar{a}} \bar{x}_{\bar{a}}^{\prime} \Leftrightarrow \bar{x}_{\bar{a}}<_{I} \bar{x}_{\bar{a}}^{\prime}$.

Notice that if consumer $\bar{a}$ is characterized by a pro-innovative preference relation, then each innovative consumption plan is better than each non-innovative plan and for any two innovative plans better is the one in which there are more innovative commodities. At the basic level, a proinnovative preference relation motivates consumers to look for new, intellectual or emotional challenges.

Theorem 1. Let a given consumer $\bar{a} \in \bar{A}$ be characterized by consumption set $\bar{X}_{\bar{a}} \neq \varnothing$ and preference relation $\preceq_{\bar{a}}$. If $\bar{\beta}_{\bar{a}} \neq \varnothing$ and $\preceq_{\bar{a}}$ is proinnovative, then $\forall \bar{x}_{\bar{a}}^{*} \in \bar{\varphi}(\bar{a}):=\left\{\bar{x}_{\bar{a}} \in \bar{\beta}_{\bar{a}}: \forall \bar{x}_{\bar{a}}^{\prime} \in \bar{\beta}_{\bar{a}} \bar{x}_{\bar{a}}^{\prime} \preceq_{\bar{a}} \bar{x}_{\bar{a}}^{\prime}\right\}, \bar{x}_{\bar{a}}^{*}$ is an innovative consumption plan.

Proof. According to assumption $\bar{\beta}_{\bar{a}} \neq \varnothing$ there are feasible innovative consumption plans in the budget set. Let us divide budget set $\bar{\beta}_{\bar{a}}$ into two disjoint subsets $\bar{\beta}_{\bar{a}}^{n}$ (a set of non-innovative plans) and $\bar{\beta}_{\bar{a}}^{I}$ (a set of innovative plans) such that $\bar{\beta}_{\bar{a}}=\bar{\beta}_{\bar{a}}^{n} \cup \bar{\beta}_{\bar{a}}^{I}$ and $\bar{\beta}_{\bar{a}}^{n} \cap \bar{\beta}_{\bar{a}}^{I}=\varnothing$. Let two consumptions plans be given: $\bar{x}_{\bar{a}}^{n} \in \bar{\beta}_{\bar{a}}^{n}$ and $\bar{x}_{\bar{a}}^{I} \in \bar{\beta}_{\bar{a}}^{I}$. Notice that for non-the inno- 
vative consumption plan $\bar{X}_{\bar{a}}^{n} \operatorname{proj}_{\mathbb{R}^{\bar{T}_{I}}}\left(\bar{X}_{\bar{a}}^{n}\right)=0$ and for the innovative consumption plan $\bar{x}_{\bar{a}}^{I} \operatorname{proj}_{\mathbb{R}^{\bar{\tau}_{I}}}\left(\bar{x}_{\bar{a}}^{I}\right)>0$ (Definition 4). Thus $\operatorname{proj}_{\mathbb{R}^{\bar{\ell}_{I}}}\left(\bar{x}_{\bar{a}}^{n}\right)<\operatorname{proj}_{\mathbb{R}^{\bar{\ell}_{I}}}\left(\bar{x}_{\bar{a}}^{I}\right)$ and $\bar{x}_{\bar{a}}^{n}<_{I} \bar{x}_{\bar{a}}^{I}$ (Definition 5 b). Since the preference relation $\preceq_{\bar{a}}$ of the consumer $\bar{a}$ is pro-innovative, there is $\bar{X}_{\bar{a}}^{n} \prec_{\bar{a}} \bar{X}_{\bar{a}}^{I} \quad$ (Definition 6) and $\bar{\varphi}(\bar{a})=\left\{\bar{x}_{\bar{a}}^{*} \in \bar{\beta}_{\bar{a}}: \bar{x}_{\bar{a}}^{*} \in \bar{\beta}_{\bar{a}}^{I}\right\}$.

The above theorem says that for consumer $\bar{a}$ is characterized by a proinnovative preference relation if there are feasible innovative consumption plans in his/her budget set, each consumption plan maximizing his/her preference relation in the budget set is innovative.

According to Schumpeter's theory, changes in consumer activities are secondary to respective changes in the production system, but in the neoSchumpeterian research path evolutionary processes are defined as changes in the multi-level and twin-track relationship between producers and consumers. Moreover, these processes include innovative changes in the consumption sphere. Thus finally a concept of an innovative extension of the consumption system will be introduced.

Let two consumption systems

$$
C=\left(A, \mathbb{R}^{\ell}, \text { Pref }, C h_{C}\right) \text {, where } C h_{C}=(x, e, \varepsilon, p, \beta, \varphi)
$$

and $C^{\prime}=\left(A^{\prime}, \mathbb{R}^{\ell^{\prime}}\right.$, Pref $\left.{ }^{\prime}, C h_{C^{\prime}}\right)$, where $C h_{C^{\prime}}=\left(x^{\prime}, e^{\prime}, \varepsilon^{\prime}, p^{\prime}, \beta^{\prime}, \varphi^{\prime}\right)$ be given.

Definition 7. Consumption system $C^{\prime}$ is called an innovative extension of system $C$, in short $C \subset_{i} C^{\prime}$, if:

$1 \ell \leq \ell^{\prime}$

$2 p=\operatorname{proj}_{\mathbb{R}^{\ell}}\left(p^{\prime}\right)$

$3 \exists a^{\prime} \in A^{\prime}$

$$
3.1 \beta_{a^{\prime}}^{I^{\prime}} \neq \varnothing
$$

$3.2 \preceq_{a^{\prime}}$ is pro-innovative

$$
3.3 \exists x_{a^{\prime}}^{\prime} \in \varphi_{a^{\prime}}^{\prime} \forall a \in A \quad \forall x_{a} \in \varphi_{a} \quad x_{a}<_{I} \quad x_{a^{\prime}}^{\prime} .
$$

Consumption system $C^{\prime}$ is an innovative extension of system $C$, if there exists at least one consumer $a^{\prime}$ with a pro-innovative preference relation (Condition 3.2) and feasible innovative consumption plans (Condition 3.1). Moreover, this consumer has at least one optimal consumption plan more 
innovative than the analogous plans being realized by the consumers in the previous consumption system $C$.

It is easy to see that, in particular when $\ell<\ell$, Definition 7 covers four cases of structural changes in the consumer sphere, i.e.

1) the introduction of a new commodity - Condition 1 ,

2) the introduction of innovative consumption plans - Condition 3.1,

3) the changing of preference relations with respect to innovative consumption plans - Condition 3.2,

4) the carrying out of the consumption plans more innovative than before - Condition 3.3.

\section{Conclusions and future research directions}

This work is coherent with currently active - in spite of Schumpeter's theory - research path which emphasizes the active role of consumers in innovation processes. This setting is coherent with the idea that economic evolution is an immensely complex process, and especially with the fact that the demand side plays an important active role in the process of innovative development.

The main findings of the present article are that:

1. There are two kinds of consumer innovativeness: one refers to the active role of the consumer as a company owner in choosing the optimal innovative production plans, second is the predisposition of the consumer to adopt innovative commodities in the consumption plans.

2. Consumer innovativeness can be defined in the formal apparatus of the modern Arrow-Debreu theory of general equilibrium and is based on the formal definition of the innovative extension of the production system and the Debreu economy.

3. Innovative changes are observed not only in the production sphere but also in the consumption system.

The conclusions drawn from the analysis of consumer innovativeness provide the ideas for future study, i.e. measuring consumer innovativeness, the role of consumer credit in economic development, and an analysis of the multi-level and twin-track relationship between producers and consumers. Moreover, the given axiomatical analysis of innovative changes in the demand sphere in the Arrow-Debreu set-up includes the basic elements of the mathematical formalism which constitute the starting point for further research on the impact of the demand sphere on the process of innovative 
development of the whole economic system, especially in the diffusion of innovation based on imitations.

\section{References}

Andersen E.S. (2007). Innovation and demand. In: Elgar Companion to NeoSchumpeterian Economics. Elgar. Cheltenham. Northampton.

Ciałowicz B., Malawski A. (2011). The Role of Banks in the Schumpeterian Innovative Evolution - an Axiomatic Set-Up. In: A. Pyka, F. Derengowski, M. da Graca (eds.). Catching Up, Spillovers and Innovation Networks in a Schumpeterian Perspective. Springer-Verlag. Pp. 31-58.

Ciałowicz B., Malawski A. (2012). The role of households in the Schumpeterian innovative evolution - an axiomatic set-up. The paper presented at The $14^{\text {th }}$ International Schumpeter Society Conference. University of Queensland. Brisbane, Australia. July 2-5.

Ciałowicz B., Malawski A. (2013). Demand driven Schumpeterian innovative evolution. In: A. Malawski (ed). Innovative Economy as the Object of Investigation in Theoretical Economics. Cracow University Press. Cracow.

Clark R.A., Goldsmith R.E. (2006). Interpersonal influence and consumer innovativeness. International Journal of Consumer Studies. Vol. 30. Issue 1. Pp. 34-43.

Debreu G. (1959). Theory of Value. Wiley. New York.

Green K., Walsh V., Tomlinson M., McMeekin A. (2002). Innovation by Demand: Interdisciplinary Approaches to the study of demand and its role in innovation. Manchester University Press.

Hurt H.T., Joseph K., Cook C. (1977). Scales for the measurement of innovativeness. Human Communication Research. Vol. 4. Issue 1. Pp. 58-65.

Malawski A. (1999). Metoda aksjomatyczna w ekonomii. Ossolineum. Wrocław.

Malawski A. (2005). A dynamical system approach to the Arrow-Debreu theory of general equilibrium. The 9th World Multi-Conference on Systemics, Cybernetics and Informatics. Proceedings. Orlando Florida. Vol. VII. Pp. 434-439.

Malawski A. (ed.). (2013). Innovative Economy as the Object of Investigation in Theoretical Economics. Cracow University Press. Cracow.

Nelson R.R., Winter S.G. (1982). An Evolutionary Theory of Economic Change. Cambridge.

Nelson R.R., Winter S.G. (2002). Evolutionary theorizing in economics. Journal of Economic Perspective 16. Pp. 23-46.

NESTA (2010). Demand and Innovation. How consumer preferences shape the innovation process. The work Foundation Working Paper. March. www.nesta.org.uk/publications/ assets/features/demand and innovation.

Rogers E.M., Shoemaker F.F. (1971). Communication of Innovativeness. The Free Press. New York.

Saam N.J. (2005). The role of consumers in innovation processes in markets. Rationality and Society. Vol. 17. Issue 3. Pp. 343-380.

Schumpeter J.A. (1961). The Theory of Economic Development. A Galaxy Book. New York. Oxford University Press. 